\title{
Inorganic Fertilizers (Ground and Foliar Application) and Organic Fertilizer: Their Effects on the Growth and Yield of Pechay (Brassica napus L. subsp. chinensis var. Black Behi)
}

\author{
Abdani D. Bandera* \\ Mindanao State University Marawi City, 9700, Philippines
}

*Corresponding Authors: Abdani D. Bandera, Mindanao State University Marawi City, Philippines

\begin{abstract}
The study was conducted to evaluate the growth and yield performance of Pechay applied with different types and levels of organic and inorganic fertilizers under different methods of application. In particular, the study aimed to evaluate the growth parameters, to determine the yield components, and to determine whether a significant difference between treatments exists on the growth and yield performance of Pechay using different nutrient sources and application methods. Randomized Complete Block Design (RCBD) was used with three replications and the experiment was conducted at Mindanao State University-Main Campus, Marawi City. Results of the study showed that $T_{2}$ (Recommended Rate (RR) Inorganic Fertilizer) plants are the tallest while $T_{1}$ (Control) plants are the shortest with a mean height of 14.56 and $8.66 \mathrm{~cm}$, respectively. T2 plants also have the highest mean growth rate of $3.015 \mathrm{~mm} /$ day, and $T_{7}(50 \%$ RR Organic Fertilizer $+50 \%$ RR Foliar Fertilizer) as the shortest with a mean growth rate of $1.237 \mathrm{~mm} /$ day. Further, $T_{5}$ (50\% RR Inorganic Fertilizer + 50\% RR Organic Fertilizer) plants show the highest mean number of leaves of 10.197, and $T_{1}$ plants are the least with a mean number of leaves of 6.867. Yield was also highest in $T_{2}$ and lowest in $T_{1}$ with a mean weight of $225.863 \mathrm{~g}$ and $50.853 \mathrm{~g}$, respectively. Moreover, the results of the study are recommended to the Philippines' Department of Agriculture (DA) and Local Government Units (LGUs) to guide the farmers and consider adopting the recommendations of this study. These are also recommended to the Department of Trade and Industry (DTI) for the consumers to identify foods free from toxic substances.
\end{abstract}

Keywords: Pechay, Organic Fertilizers, Inorganic Fertilizers, Ground and Foliar Application, Urban Gardening, Randomized Complete Block Design

\section{INTRODUCTION}

Types and levels of fertilizer applied to crops are very important in crop production and play an important role in cropping systems. Relying on inorganic or chemical fertilizers is a major constraint due to its prohibitive cost though identified as an important factor in meeting the food requirements of a growing population.

In recent years there is a growing trend to reduce the use of mineral fertilizers, especially soil applied nutrients such as nitrogen $(\mathrm{N})$, phosphorus $(\mathrm{P})$ and potassium $(\mathrm{K})$ and their use had decreased by seven times. Moreover, there is also increasing demand for organically-grown farm products. These create preconditions to recognize the importance of foliar fertilization and the use of organic fertilizers as an alternative to meet plant nutrient demand during the growing season (Kerin and Berova, 2003).

Foliar fertilization is an important tool for the sustainable and productive management of crops. In recent years, foliar fertilizers, especially organic ones, have proliferated in the agricultural fertilizer market (Eroy, 2015). Interest on foliar fertilization has risen because of the many advantages of the methods of application of foliar nutrients, such as rapid and effective response to plant needs, regardless of soil conditions (Kerin \& Berova, 2003). However, few studies have been conducted to compare the effects of both ground and foliar application of fertilizers.

According to Tukey and Marczynski (1984), combined soil and foliar applications should be recommended to increase both plant productivity and yield quality. Kuepper (2003) also emphasized that foliar application of fertilizers is becoming more prevalent as practice in agricultural crop production because it is more directly targeted and potentially more friendly to the environment in contrast to soil fertilization. In fact, Johnson et al. (2001) suggested that supplying $\mathrm{N}$ to peach trees 
Inorganic Fertilizers (Ground and Foliar Application) and Organic Fertilizer: Their Effects on the Growth and Yield of Pechay (Brassica napus L. subsp. chinensis var. Black Behi)

using a combination of soil and foliar $\mathrm{N}$ fertilizers leads to optimal plant responses and limited environmental pollution risks.

Pechay (Brassica napus L. var. Black Behi) is major vegetable crop rich in vitamin C and contains significant amounts of nitrogen compounds known as indoles, as well as fiber-both of which appear to lower the risk of various forms of cancer. It has been selectively cultivated to produce a plant that has an exceptionally short life cycle of 30-45 days (Acero, 2013).

So far, crop production fertilizer studies focused both on organic and inorganic types. Limited studies had been made comparing reactions of plants to solid and liquid fertilizers and to different methods of application. Hence, this study focused on the effects of using different types and levels of organic and inorganic fertilizers under different methods of application to the growth and yield of Pechay and to determine if significant differences exist between and among treatments.

\section{LITERATURE REVIEW}

In a recent review, Fernández and Brown (2013) stated that foliar fertilization is an agricultural practice of increasing importance. In theory, application of nutrient sprays may indeed be an environmentally friendly fertilization method since the nutrients are directly delivered to the plant in limited amounts, thereby helping to reduce the environmental impact associated with soil fertilization. However, response to foliar sprays is often variable and not reproducible due to the existing lack of knowledge of many factors related to the penetration of the leaf-applied solution.

This fact causes farmers to shift to either organic fertilizers or inorganic fertilizers. Buckman and Brady (1974) reported that organic fertilizer increases the cation exchange capacity of the soil. Aside from its ability to supply nutrients, organic fertilizers are also capable of improving the physical, chemical, and biological properties of soil which could significantly improve the growth and development of plants. Pascual et al. (2013) pointed out that organic matter is an excellent source of plant-available nutrients and their addition to soil could maintain high microbial populations and activities.

\subsection{T. harzianum + E. fetida Compost Application}

Studies made by Bercero et al. (2014) found that application of T. harzianum + E. fetida compost produced comparable results as to the number of leaves, leaf width, leaf length, fresh weight and dry weight with the positive control (synthetic organic fertilizer (Urea) at 0.65 grams' plant-1) indicating that it is a good alternative to application of inorganic fertilizer to the growth of Pechay. Compost derived from the application of T. harzianum + Vermi worms is highly recommended to produce Pechay.

\subsection{Vermicompost Application}

Ahirwar and Hussain (2015) studied the effect of vermicompost on growth, yield, and quality of vegetable crops. Results showed that growth of vegetable transplants was positively affected by addition of vermicompost, perhaps by altering the nutritional balance of the medium. Transplant quality was improved in peppers and eggplants while tomato transplant quality was slightly reduced. Also, there were no significant differences in field performance. Hence, vermicomposting is a sustainable technique for solid waste disposal.

Nurhidayati et al. (2016) studied the yield and quality of cabbage (Brassica oleracea L.var. capitata) under organic growing media using vermicompost and earthworm Pontoscolex corethrurus inoculation. Results showed that the application of vermicompost combined with inoculation of earthworm $P$. corethrurus significantly increased total biomass, marketable weight, crop diameter, and harvest index compared with the cabbage grown in inorganic media as well as the quality of cabbage which was determined by sugar and vitamin $C$ content and storage loss. Each vermicompost provided the highest yield and quality at different earthworm population. Vermicompost made from the mixture of cow manure and vegetables residue gave a high yield and quality cabbage with population of $P$. corethrurus by 0-25 indiv.m-2. Moreover, vermicompost made from the mixture of cow manure and leaf litter with population of $P$. corethrurus by 50 indiv.m-2 gave a high yield and quality cabbage. Lastly, vermicompost made from the mixture of cow manureza, vegetable residue, and leaf litter gave a high yield cabbage without inoculation earthworm $P$. corethrurus and with population of $P$. corethrurus by 75-100 indiv.m-2 for a high-quality cabbage.

Kaur et al. (2015) studied the effect of vermicompost and vermiwash on growth of vegetables and found that organic waste material processed by the naturally occurring earthworm should be used to 
Inorganic Fertilizers (Ground and Foliar Application) and Organic Fertilizer: Their Effects on the Growth and Yield of Pechay (Brassica napus L. subsp. chinensis var. Black Behi)

produce vermicompost which will supply nutrients and other soil stimulants for plant growth and improve soil quality. Vermiculture provides the best answer for ecological agriculture, which is synonymous with "sustainable agriculture".

Arancon and Edwards (2005) studied the effects of vermicompost on plant growth and found that when used at lower substitution rates, vermicompost can increase growth, flowering and yields of vegetable and ornamental crops. Similarly, vermicompost applied at very low rates e.g. $2.5 \mathrm{t} / \mathrm{ha}$ or 5 tha can significantly increase growth and yields of highly valuable vegetable and fruit crops in the field. The effects of vermicompost on plants are not solely attributed to the quality of mineral nutrition provided but also to its other growth regulating components such as plant growth hormones and humic acids. Moreover, the application of vermicompost in the field enhances the quality of soils by increasing microbial activity and microbial biomass which are key components in nutrient cycling, production of plant growth regulators and protecting plants soil-borne disease and arthropod pest attacks.

Vermicompost is worm castings or digested excretions, and is largely used by gardeners and landscapers as a soil amendment. These castings originate from organic materials, which the worms feed on (Tejada et al., 2010). Once ingested the organic material undergoes enzymatic digestion along with several other processes to ultimately create a casting. Vermicompost contains many plant available nutrients, and research indicates castings improve soil structure by enhancing soil porosity, aeration, and moisture holding capacity resulting in enhanced plant growth (Tejada et al., 2010; Atiyeh et al., 2000; Handreck, 1986; Grapelli et al., 1985). Aging of vermicompost has been studied focusing on microbiological or physical/chemical changes for up to 60 days of aging (Aira et al., 2007; Hindell et al., 1997; Parle, 1963).

Vermicompost is finely divided peat-like materials with high porosity, aeration, drainage, waterholding capacity (Tejada et al., 2010). Handreck (1986) reported that vermicompost tended to have $\mathrm{pH}$ values near neutrality which may be due to the production of carbon dioxide and organic acids produced during microbial metabolism. They also reported that their moisture content was reduced progressively during vermicomposting giving final moisture contents between $45 \%$ and $60 \%$, the ideal moisture contents for land-applied composts (Tejada et al., 2010).

Arancon et al. (2004) studied the agronomic impacts of vermicompost and inorganic (chemical) fertilizers on strawberries when applied separately and in combination. Vermicompost was applied at 10 tons/ha while the inorganic fertilizers (nitrogen, phosphorus, potassium) at $85(\mathrm{~N})-155(\mathrm{P})-125(\mathrm{~K})$ $\mathrm{kg} / \mathrm{ha}$. While there was not much difference in the dry shoot weight of strawberries, the yield of marketable strawberries and the weight of the largest fruit was greater on plants in plots grown on vermicompost as compared to inorganic fertilizers in 220 days after transplanting. In addition, there were more runners and flowers on plants grown on vermicompost. Also, farm soils applied with vermicompost had significantly greater microbial biomass than the one applied with inorganic fertilizers.

Vermicompost has demonstrated consistently beneficial effects on plant growth independent of nutrient transformations and availability (Dominguez \& Gomez-Brandon, 2012). Theunissen et al. (2010) found that vermicompost contained plants nutrients including N, P, K, Ca, Mg, S, Fe, Mn, Zn, $\mathrm{Cu}$ and $\mathrm{B}$, the uptake of which had positive effects on plant nutrition, photosynthesis, chlorophyll content of the leaves and improves the nutrient content of the different plant components (roots, shoots and the fruits).

Webster et al. (2005) studied the agronomic impact of vermicompost on cherries and found that it increased yield of cherries for three (3) years after single application. Application of vermicompost in soil builds up fertility and restore its vitality for long time and its further use can be reduced to a minimum after some years of application in farms. Buckerfield and Webster (1998) found that wormworked waste (vermicompost) boosted grape yield by two-fold as compared to chemical fertilizers.

\subsection{Organic Fertilizer Application}

Lim and Vimala (2012) studied the growth and yield responses of four leafy vegetables to organic fertilizer. Results showed that organic fertilizer as the sole source of nutrients can give yields that are higher or comparable to inorganic fertilizer. Thus, an organic grower need not fear reduced yields, if 
Inorganic Fertilizers (Ground and Foliar Application) and Organic Fertilizer: Their Effects on the Growth and Yield of Pechay (Brassica napus L. subsp. chinensis var. Black Behi)

the correct rate of organic fertilizer is applied. The optimum responses of leafy vegetables to organic fertilizer rate was about $30 \mathrm{t} / \mathrm{ha}$ of poultry manure for leaf mustard, kangkung and lettuce and $36 \mathrm{t} / \mathrm{ha}$ for chinese spinach.

Zainab et al. (2016) studied the effects of organic and inorganic fertilizers on the growth of $\mathrm{NH}-\mathrm{Ae}$ 47-4 variety of okra. Results obtained from the experiment showed that the effect of the treatments were significantly different from the control for all the parameters accessed with urea fertilizer having least effect. Plants treated with poultry litters have best performance by recording the highest fresh and dry weight $(0.39 \mathrm{~g})$ at 4 weeks after planting (WAP); highest stem height $29.33 \mathrm{~cm}$ for all the concentrations applied.

Dalal et al. (2014) studied the growth, yield, and quality of vegetables under chemical and organic farming. Results showed that in the final measurement, both two vegetables in organic fertilization treatments grew better and resulted in a final higher total yield, shoot length and branches than those in chemical fertilizer treatments, which was attributed to the high nutrient sustainability of organic fertilizer and the improved biological properties of the soil. Macronutrients Nitrogen $(\mathrm{N})$, Phosphorous (P), Potassium (K) and Carbon (C) were increased by the application of organic manure. Total microbial count increases by using the organic fertilizers, shown the indication of healthy soil. Results of this experiment showed that chemical fertilizers were less suitable as compared to organic fertilizers. It is recommended that vegetables can be grown successfully with supplementation of organic fertilizers.

Subler and Edwards (undated) reported that the best plant growth responses are when organic fertilizer and traditional fertilizers are used together. In addition, Prado and Sampaga (2013) studied the response of Pechay, (Brassica rapa) to organic fertilizer under DMMMSU-NLUC condition, La Union, Philippines. Pechay, when applied with organic inputs for its growth, has comparative advantage over that of the farmers' practice of using urea. Although statistically insignificant in the ANOVA test, the differences in values favor the use of organic inputs. Likewise, raw recipes for Pechay are more nutritious, hence safer if organically grown due to the absence of chemicals. Moreover, growing organically is helping maintain a clean and safe environment to live in.

\subsection{Different Levels of Compost Fertilizer}

A study conducted by Gonzales et al. (2015) on the response of Pechay (Brassica napus L.) to different levels of compost fertilizer concluded that the application of 75\% Pure Garden Soil: 25\% Pure Compost provided the best growth and yield performance of Pechay in terms of leaf area and fresh weight. The result of the study showed that application of organic fertilizer greatly enhanced growth and yield performance of Pechay. The application of organic fertilizer in Pechay specifically, compost is recommended since it influences its growth and yield, especially on the leaf area and fresh weight.

Natsheh and Mousa (2014) studied the effect of organic and inorganic fertilizers application on soil and cucumber (Cucumis sativus L.) plant productivity. Results showed that the application of compost improved the soil characteristics; increased soil productivity and organic matter content. The experimental results confirmed that the use of organic fertilizers increased the crop productivity.

\subsection{Inorganic Fertilizer Application}

Eifediyi and Remison (2010) studied the effects of inorganic fertilizer on the yield of two varieties of cucumber (Cucumis sativus L.). Results revealed significant differences $(\mathrm{P}<0.05)$ among the varieties in terms of vine length, number of branches and leaf area. The growth and yield attributes of cucumber including the vine length, number of leaves per plant, number of branches, leaf area, number of fruits per plant, fruit length, fruit girth, fruit weight per plant, fruit number per plant and total yield per hectare increased significantly $(\mathrm{P}<0.05)$ with increase in inorganic fertilizer application up to the highest level.

According to Pascual et al. (2013), to produce high yield, most growers use synthetically-based products, thus, the possibility of pesticides and chemical residue accumulation is very serious that poses threat to human health.

Synthetically-based fertilizers are the most common fertilizers used by the farmers. However, its use incurs a high cost and its supply is sometimes limited that many farmers now are still adapting the idea of using organic fertilizers no matter how long and laborious is the preparation (Gonzales et al., 2015). 
Inorganic Fertilizers (Ground and Foliar Application) and Organic Fertilizer: Their Effects on the Growth and Yield of Pechay (Brassica napus L. subsp. chinensis var. Black Behi)

Fertilizer application using either inorganic or organic fertilizer sources is one of the most common cultural management practices in vegetable production. According to Masarirambi et al. (2010), commercial and subsistence farming has been and is still relying on the use of inorganic fertilizers for growing crops. This is because they are easy to use, quickly absorbed and utilized by crops. However, these fertilizers are believed to contribute substantially to human, animal, food intoxication and environmental instability or degradation (Masarirambi et al., 2010).

Omidire et al. (2015) conducted a study entitled "Assessing the Impacts of Inorganic and Organic Fertilizer on Crop Performance Under a Microirrigation-Plastic Mulch Regime". Results showed that the inorganic fertilizer had higher yields (lbs/acre) than organic fertilizer. The addition of microbes to the inorganic fertilizer significantly increased the numbers of cucumbers and okra per acre. Overall, the "Farmer mix" with or without the addition of microbes significantly increased yields for all crops compared to the organic-based fertilizer.

Lian et al. (2017) studied the effects of different proportions of inorganic fertilizer and organic fertilizer on yield and quality of amaranth. Results showed that inorganic fertilizer is a kind of fast, high nutrient chemicals, but too much inorganic fertilizers will lead to high levels of nitrate in vegetables, affecting the quality of vegetables. Organic fertilizers can provide a more comprehensive and lasting nutrients that needed for crop growth and development, but too much also to cause a decline in quality of vegetable. Many studies have shown that organic and inorganic fertilizer can complement each other, which can provide continuous, comprehensive nutrients to the growth of crops to increase crop yield and quality.

Ogundare et al. (2015) studied the growth and fruit yield of tomato as influenced by combined use of organic and inorganic fertilizer in Kabba, Nigeria. Result obtained from parameters studied (plant height, leaf numbers, branch number, stem girth, fruit number per plant and fruits weight) revealed that tomato performed better $(\mathrm{P}<0.05)$ with the application of $125 \mathrm{~kg} / \mathrm{ha} \mathrm{NPK}+3 \mathrm{t} / \mathrm{ha}$ poultry manure application. The study showed that use of inorganic and organic fertilizer had better effects on growth and yield of tomato. Therefore, for good yield and better productivity of tomato, a combination of $125 \mathrm{~kg} / \mathrm{ha}$ NPK fertilizer $+3 \mathrm{t} / \mathrm{ha}$ poultry waste is recommended for tomato production in the study area.

\subsection{Foliar Fertilizer Application}

Zaniewiez-Bajkowska et al. (2010) studied the yield quality of melon (Cucumis melo L.). Results showed that foliar-fertilized plants deliver high yields of good quality at lower rates of mineral fertilization. In horticultural practice foliar fertilization is also recommended as the most effective method of supplying plants with nutrients under deficiency conditions. An application of the foliar fertilizers reduced the total sugar and monosaccharides content in melon fruit. Regardless of the kind of foliar feeding, driest matter in the fruit was produced by 'Pacstart', total sugar and monosaccharides by 'Yupi' and ascorbic acid by 'Legend'.

Rahman et al. (2015) studied "Review of Foliar Feeding in Various Vegetables and Cereal Crops Boosting Growth and Yield Attributes". Results showed that foliar application of macro and micro nutrients play an important role in the production of good crop and higher yield.

Mandić et al. (2015) studied the effect of foliar fertilization on soybean grain yield. Results showed that foliar fertilizers significantly increased the values for all quantitative traits. Ferticare I is more effective than Wuxal super in soybean because this fertilizer has higher concentration of macronutrients. Foliar fertilization of soybean reduced the negative impact of small amounts of rainfall during the summer months on grain yield.

Chaurasia et al. (2005) studied the effect of foliar application of water-soluble fertilizers on growth, yield, and quality of tomato (Lycopersicon esculentum L.). Results showed that the application of 5 foliar sprays of water-soluble fertilizers significantly increased the plant height, number of branches, Number of fruits, average fruit weight, fruit length, fruit diameter, TSS, yield and the net profit of tomatoes. The maximum plant height, number of branches/plant, fruit length, yield, net profit along with maximum C:B ratio were recorded by 5 foliar sprays of water soluble liquid fertilizers 19:09:19 followed by NPK 19:19:19. The minimum values in all the parameters were recorded in the control having only recommended dose of fertilizer.

Wójcik (2004) studied the uptake of mineral nutrients from foliar fertilization. Results of the study showed that foliar fertilization is most effective when soil nutrient availability is low, topsoil dry, and 
Inorganic Fertilizers (Ground and Foliar Application) and Organic Fertilizer: Their Effects on the Growth and Yield of Pechay (Brassica napus L. subsp. chinensis var. Black Behi)

root activity during the reproductive stage is decreased. Foliar fertilization is also successful in increasing content of fruit $\mathrm{Ca} 2+$ and cereal grain protein. It is proposed that this treatment should be recommended in the integrated plant production because it is environment friendly and increases productivity and yield quality.

\section{MethodologY}

\subsection{Research Design}

The experiment was laid out using Randomized Complete Block Design (RCBD) with seven treatments replicated thrice. A total area of $10 \mathrm{~m} \times 12 \mathrm{~m}\left(120 \mathrm{~m}^{2}\right)$ was divided into three blocks each representing one replication. Distance between blocks is one (1) meter. Shown below are the treatments and their respective amount and types of fertilizers used.

\subsection{Treatments}

There were seven (7) treatment combinations used in the study. Each treatment was replicated three (3) times and consisted of fifteen (15) pots per replicate. The total number of treatment replications, each considered an experimental unit, was twenty-one (21).

Randomization was done through drawing of lots. The lay-out shown in Figure 1 below was done following the step-by-step procedure in RCBD experiment since it was conducted in an uncontrolled environment. The treatment combinations are the following:

\begin{tabular}{|l|l|}
\hline $\mathbf{T}_{\mathbf{1}}$ & $=$ Control \\
\hline $\mathbf{T}_{\mathbf{2}}$ & $=$ Recommended Rate (RR) Inorganic Fertilizer $\left(60-40-60 \mathrm{~kg} \mathrm{~N}, \mathrm{P}_{2} \mathrm{O}_{5}, \mathrm{~K}_{2} \mathrm{O} / \mathrm{ha}\right)$ \\
\hline $\mathbf{T}_{3}$ & $=$ RR Organic Fertilizer (30t/ha; 30g/pot) \\
\hline $\mathbf{T}_{\mathbf{4}}$ & $=$ RR Foliar Fertilizer (60ml/16 li $\left.\mathrm{H}_{2} \mathrm{O}\right)$ \\
\hline $\mathbf{T}_{5}$ & $=50 \%$ RR Inorganic Fertilizer $\left(30-20-30 \mathrm{~kg} \mathrm{~N}, \mathrm{P}_{2} \mathrm{O}_{5}, \mathrm{~K}_{2} \mathrm{O} / \mathrm{ha}\right)+50 \%$ RR Organic Fertilizer \\
& $(15 \mathrm{t} / \mathrm{ha} ; 15 \mathrm{~g} /$ pot)
\end{tabular}

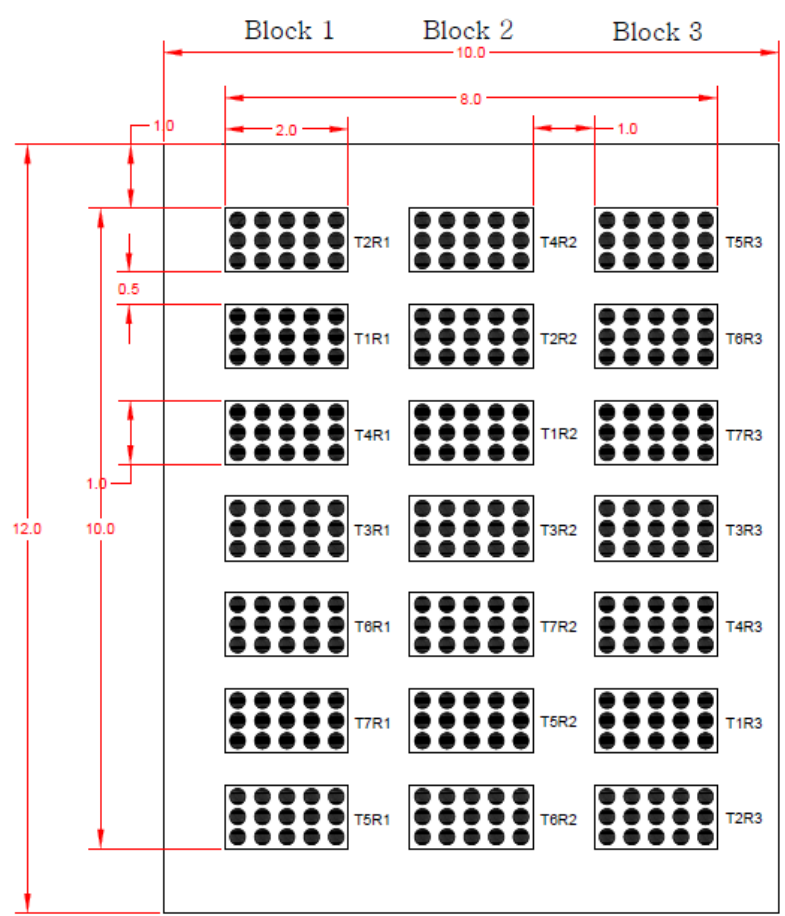

Figure1. Field Layout

\subsection{Materials}

The following materials were used in this study: plastic pots, fertilizer materials (complete fertilizer, muriate of potash, ammonium sulfate, foliar fertilizer (crop giant) and vermicompost), garden soil, 
Inorganic Fertilizers (Ground and Foliar Application) and Organic Fertilizer: Their Effects on the Growth and Yield of Pechay (Brassica napus L. subsp. chinensis var. Black Behi)

spade, standard ruler, weighing scale, and Pechay seeds (Brassica napus L. var. Black Behi). Black Behi is an all-season variety adapted to both lowland and highland. It can be harvested in 25 to 39 days after sowing.

\subsection{Cultural Management}

The variety used in this study was Black Behi from East-West Company. A total of three-hundred fifteen (315) pots were used corresponding to the number of treatments and the number of replications per treatment. Each pot was 8 " in diameter and 10" in depth. Soils used in this study were taken from the Dairy Farm of the Mindanao State University-Marawi. The soil was homogenized or mixed thoroughly to ensure that each pot for each treatment and replicate was filled with the same soil quality.

Three seeds were sown per pot. Thinning was done to keep one plant per pot as the seedlings developed their first true leaves. Watering was done uniformly and as necessary for all treatments throughout the study period. The amount of water applied per pot was $200 \mathrm{ml}$ per watering. Insect pests were controlled by a combination of handpicking and spraying with crushed /pounded chili solution. The pots were kept weed-free by manual hand pulling where needed and prior to treatment application. Plants were harvested by hand-pulling 45 days after sowing.

\subsection{Fertilizer Application/Application of Treatments}

Treatment, rate, method, and time of application of fertilizer

\begin{tabular}{|c|c|c|c|c|}
\hline Treatment & Description & $\begin{array}{c}\text { Rate of } \\
\text { Application per } \\
\text { Plant }\end{array}$ & $\begin{array}{l}\text { Method of } \\
\text { Application }\end{array}$ & $\begin{array}{c}\text { Time of } \\
\text { Application }\end{array}$ \\
\hline T1 & Control & - & - & - \\
\hline $\mathbf{T 2}$ & $\begin{array}{l}\text { Rec. Rate (RR) Inorganic } \\
\text { Fertilizer (60-40-60 kg N, } \mathrm{P}_{2} \mathrm{O}_{5} \text {, } \\
\left.\mathrm{K}_{2} \mathrm{O} / \mathrm{ha}\right)\end{array}$ & $\begin{array}{l}\text {-2.86 g Complete } \\
\text { (C) } \\
-3.33 \mathrm{~g} \text { Muriate of } \\
\text { Potash (MOP) } \\
-9.52 \mathrm{~g} \\
\text { Ammonium } \\
\text { Sulfate (AS) }\end{array}$ & Side dress & $\begin{array}{l}-7 \text { days after } \\
\text { planting (DAP) } \\
\text { for } \mathrm{C} \text { and MOP } \\
-14 \text { days DAP for } \\
\text { AS }\end{array}$ \\
\hline T3 & $\begin{array}{l}\text { RR Organic Fertilizer (30t/ha; } \\
\text { 30g/pot) }\end{array}$ & $-30 \mathrm{~g}$ & Basal & -Before planting \\
\hline T4 & $\begin{array}{l}\text { RR Foliar Fertilizer }(60 \mathrm{ml} / 16 \text { li } \\
\left.\mathrm{H}_{2} \mathrm{O}\right)\end{array}$ & $\begin{array}{l}33.33 \mathrm{ml} \text { at a rate } \\
(3.75 \mathrm{ml} \text { per liter } \\
\text { of water })\end{array}$ & -Foliar spray & $\begin{array}{l}-7 \text { DAP } \\
-14 \text { DAP } \\
-21 \text { DAP }\end{array}$ \\
\hline T5 & $\begin{array}{l}\text { 50\% RR Inorganic Fertilizer (30- } \\
\left.20-30 \mathrm{~kg} \mathrm{~N}, \mathrm{P}_{2} \mathrm{O}_{5}, \mathrm{~K}_{2} \mathrm{O} / \mathrm{ha}\right)+ \\
50 \% \text { RR Organic Fertilizer } \\
(15 \mathrm{t} / \mathrm{ha} ; 15 \mathrm{~g} / \mathrm{pot})\end{array}$ & $\begin{array}{l}-1.43 \text { g Complete } \\
\text { (C) } \\
-1.67 \mathrm{~g} \text { Muriate of } \\
\text { Potash (MOP) } \\
-4.76 \mathrm{~g} \\
\text { Ammonium } \\
\text { Sulfate (AS) } \\
-15 \mathrm{~g} / \mathrm{pot}\end{array}$ & $\begin{array}{l}\text {-Side dress } \\
\text {-basal } \\
\text { application }\end{array}$ & $\begin{array}{l}-7 \text { days after } \\
\text { planting (DAP) } \\
\text { for C and MOP } \\
-14 \text { days DAP for } \\
\text { AS } \\
\text {-before planting }\end{array}$ \\
\hline T6 & $\begin{array}{l}50 \% \text { RR Inorganic Fertilizer (30- } \\
\left.20-30 \mathrm{~kg} \mathrm{~N}, \mathrm{P}_{2} \mathrm{O}_{5}, \mathrm{~K}_{2} \mathrm{O} / \mathrm{ha}\right)+ \\
50 \% \text { RR Foliar Fertilizer }(30 \mathrm{ml} / \\
\left.16 \mathrm{li} \mathrm{H}_{2} \mathrm{O}\right)\end{array}$ & $\begin{array}{l}-1.43 \mathrm{~g} \text { Complete } \\
\text { (C) } \\
-1.67 \mathrm{~g} \text { Muriate of } \\
\text { Potash (MOP) } \\
-4.76 \mathrm{~g} \\
\text { Ammonium } \\
\text { Sulfate (AS) } \\
-33.33 \mathrm{ml} \text { at a rate } \\
\text { (1.88 ml per liter } \\
\text { of water) }\end{array}$ & $\begin{array}{l}\text {-Side dress } \\
\text {-Foliar spray }\end{array}$ & $\begin{array}{l}-7 \text { days after } \\
\text { planting (DAP) } \\
\text { for C and MOP } \\
-14 \text { days DAP for } \\
\text { AS } \\
-7 \text { DAP } \\
-14 \text { DAP } \\
-21 \text { DAP }\end{array}$ \\
\hline T7 & $\begin{array}{l}50 \% \text { RR Organic Fertilizer } \\
(15 \mathrm{t} / \mathrm{ha} ; 15 \mathrm{~g} / \mathrm{pot})+50 \% \mathrm{RR} \\
\text { Foliar Fertilizer }\left(30 \mathrm{ml} / 16 \mathrm{li}_{2} \mathrm{O}\right)\end{array}$ & $\begin{array}{l}-15 \mathrm{~g} / \mathrm{pot} \\
-33.33 \mathrm{ml} \text { at a rate } \\
(1.88 \mathrm{ml} \text { per liter } \\
\text { of water })\end{array}$ & $\begin{array}{l}\text {-basal } \\
\text { application } \\
\text {-foliar spray }\end{array}$ & $\begin{array}{l}\text {-before planting } \\
\text { 7 DAP } \\
\text {-14 DAP } \\
\text {-21 DAP }\end{array}$ \\
\hline
\end{tabular}

* The weight of soil per pot is $2 \mathrm{~kg}$

*The weight of soil in 1 ha is $2,000,000 \mathrm{~kg}$ 
Inorganic Fertilizers (Ground and Foliar Application) and Organic Fertilizer: Their Effects on the Growth and Yield of Pechay (Brassica napus L. subsp. chinensis var. Black Behi)

\subsection{Data Gathering Procedures}

\section{Growth Parameters}

1.1. Number of Leaves per plant

This was taken by counting the number of leaves per plant weekly after first treatment application.

1.2. Plant Height

This was taken by measuring from one inch from the base of the plant up to the tip of the highest leaf in weekly interval after first treatment application.

\section{Yield Components}

2.1. Weight of marketable plant (g)

This was taken by weighing the marketable plants.

2.2. Weight of non-marketable plants (g)

This was taken by weighing the non-marketable plants.

2.3. Total weight of the crop (g)

This was taken by adding the marketable and non-marketable weight of the plants.

\subsection{Data Analysis}

\section{Analysis of Variance (ANOVA) for Randomized Complete Block Design (RCBD)}

ANOVA was done for all the data gathered. The data which show significance were compared among treatments by using Tukey Test.

2. Tukey Test (or Tukey procedure), also called Tukey's Honest Significant Difference Test, is a post-hoc test based on the student range distribution. To find out which specific group's means (compared with each other) are different after running an ANOVA, Tukey Test should be employed. The test compares all possible pairs of means.

\section{RESULTS AND DISCUSSION}

\subsection{Growth Parameters of Pechay}

\subsubsection{Plant Height (cm)}

\subsubsection{Plant Height at 14 Days After Emergence (DAE)}

The plant height of Pechay 14 DAE was significantly influenced by different types, levels, and methods of application of fertilizers. As shown in Table 1 plants grown under $\mathrm{T}_{3}$ (RR Organic Fertilizer (30t/ha; 30g/pot)) were significantly taller with a mean height of $8.12 \mathrm{~cm}$ than all others except $\mathrm{T}_{4}$ and $\mathrm{T}_{7}$ the latter also having organic fertilizer. Shortest plants were observed in $\mathrm{T}_{1}$ (Control) with a mean height of $3.09 \mathrm{~cm}$. Moreover, Table 1 shows that $T_{3}$ (RR Organic Fertilizer) mean plant height is not significantly different from $\mathrm{T}_{4}\left(\mathrm{RR}\right.$ Foliar Fertilizer $\left.\left(60 \mathrm{ml} / 16 \mathrm{li} \mathrm{H}_{2} \mathrm{O}\right)\right)$ and $\mathrm{T}_{7}(50 \% \mathrm{RR}$ Organic Fertilizer $+50 \%$ RR Foliar Fertilizer).

Table1. Tukey HSD (Effect of Different Fertilizer Types, Levels and Mode of Application on the Mean Plant Height of Pechay (cm) at 14 Days After Emergence (DAE) with Three Replications in RCBD)

\begin{tabular}{|l|c|}
\hline \multicolumn{1}{|c|}{ Treatments } & Mean Plant Height in $\mathbf{~ c m}^{\mathbf{a}}$ \\
\hline T1(Control(Garden Soil)) & $3.09 \mathrm{~d}$ \\
\hline T2(RR Inorganic Fertilizer) & $6.12 \mathrm{c}$ \\
\hline T3(RR Organic Fertilizer) & $8.12 \mathrm{a}$ \\
\hline T4(RR Foliar Fertilizer) & $7.04 \mathrm{abc}$ \\
\hline T5(50\% RR Inorganic Fertilizer + 50\% RR Organic Fertilizer) & $6.83 \mathrm{bc}$ \\
\hline T6(50\% RR Inorganic Fertilizer + 50\% RR Foliar Fertilizer) & $6.76 \mathrm{bc}$ \\
\hline T7(50\%rRR Organic Fertilizer +50\% Foliar Fertilizer) & $7.49 \mathrm{ab}$ \\
\hline
\end{tabular}

a Average of three replications

In the same column, means followed by a common letter(s) are not significantly different at $5 \%$ level by Tukey HSD test.

This conforms with the study of Dalal et al. (2014) where vegetables applied with organic fertilizer grew better which resulted to higher total yield, shoot length, and branches than those applied with chemical fertilizers. Prado and Sampaga's (2013) study on the response of Pechay to organic fertilizer under DMMMSU-NLUC condition, La Union, Philippines also had similar results where the application of organic inputs for the growth development has comparative advantage over that of the farmers' practice of using urea. Moreover, the organically-fertilized plants being the tallest jibes with 
Inorganic Fertilizers (Ground and Foliar Application) and Organic Fertilizer: Their Effects on the Growth and Yield of Pechay (Brassica napus L. subsp. chinensis var. Black Behi)

a study by Gonzales et al. (2015) where 25\% pure compost provided the best growth and yield performance of Pechay in terms of leaf area and fresh weight.

\subsubsection{Plant Height at 21 Days After Emergence (DAE)}

The plant height 21DAE was significantly influenced by different types, levels, and methods of application of fertilizers as shown in Table 2. The table reveals that plants grown in $\mathrm{T}_{2}$ (RR Inorganic Fertilizer (60-40-60 $\mathrm{kg} \mathrm{N}, \mathrm{P}_{2} \mathrm{O}_{5}, \mathrm{~K}_{2} \mathrm{O} / \mathrm{ha}$ )) were significantly the tallest versus all other treatments with a mean height of $9.85 \mathrm{~cm}$. significantly shortest plants were observed in $\mathrm{T}_{1}$ (Control) with a mean height of $4.99 \mathrm{~cm}$.

Table2. Tukey HSD (Effect of Different Fertilizer Types, Levels and Mode of Application on the Mean Plant Height of Pechay (cm) at 21 Days after Emergence (DAE) with Three Replications in RCBD)

\begin{tabular}{|l|c|}
\hline \multicolumn{1}{|c|}{ Treatments } & Mean Plant Height in $\mathbf{c m}^{\mathbf{a}}$ \\
\hline T1(Control(Garden Soil)) & $5.00 \mathrm{e}$ \\
\hline T2(RR Inorganic Fertilizer) & $9.85 \mathrm{a}$ \\
\hline T3(RR Organic Fertilizer) & $8.44 \mathrm{~d}$ \\
\hline T4(RR Foliar Fertilizer) & $8.44 \mathrm{~d}$ \\
\hline T5(50\% RR Inorganic Fertilizer + 50\% RR Organic Fertilizer) & $9.26 \mathrm{~b}$ \\
\hline T6(50\% RR Inorganic Fertilizer + 50\% RR Foliar Fertilizer) & $9.34 \mathrm{~b}$ \\
\hline T7(50\%rRR Organic Fertilizer +50\% Foliar Fertilizer) & $8.88 \mathrm{c}$ \\
\hline
\end{tabular}

a Average of three replications

In the same column, means followed by a common letter(s) are not significantly different at $5 \%$ level by Tukey HSD test.

The results are similar with the findings of Eifediyi and Remison (2010) where use of inorganic fertilizer on cucumber revealed significant differences in terms of vine length, number of branches, and leaf area. This is followed by Pechay plants grown in $\mathrm{T}_{6}(50 \%$ RR Inorganic Fertilizer+ $50 \%$ RR Foliar Fertilizer) andT 5 (50\% RR Inorganic Fertilizer $+50 \%$ RR Organic Fertilizer) which were also $50 \%$ inorganic fertilize-treated plants. Again, $\mathrm{T}_{1}$ plants (Control) receiving no fertilizer were the shortest.

\subsubsection{Plant Height at 28 Days After Emergence (DAE)}

Plant height at 28 DAE was significantly influenced by different types, levels, and methods of application of fertilizers. As shown in Table 3, plants grown in $T_{2}$ (RR Inorganic Fertilizer (60-40-60 $\mathrm{kg} \mathrm{N}, \mathrm{P}_{2} \mathrm{O}_{5}, \mathrm{~K}_{2} \mathrm{O} / \mathrm{ha}$ )) were significantly the tallest with a mean height of $14.02 \mathrm{~cm}$. The shortest plants were observed in $\mathrm{T}_{1}$ (Control) with a mean height of $7.93 \mathrm{~cm}$. Again, this conforms to the study byEifediyi and Remison (2010) where cucumber plants applied with inorganic fertilizers showed superior vegetative growth.

Table3. Tukey HSD (Effect of Different Fertilizer Types, Levels and Mode of Application on the Mean Plant Height of Pechay (cm) at 28 Days after Emergence (DAE) with Three Replications in RCBD)

\begin{tabular}{|l|c|}
\hline \multicolumn{1}{|c|}{ Treatments } & Mean Plant Height in cm \\
\hline T1(Control(Garden Soil)) & $7.93 \mathrm{~g}$ \\
\hline T2(RR Inorganic Fertilizer) & $14.02 \mathrm{a}$ \\
\hline T3(RR Organic Fertilizer) & $12.80 \mathrm{~d}$ \\
\hline T4(RR Foliar Fertilizer) & $13.76 \mathrm{~b}$ \\
\hline T5(50\% RR Inorganic Fertilizer + 50\% RR Organic Fertilizer) & $11.40 \mathrm{e}$ \\
\hline T6(50\% RR Inorganic Fertilizer + 50\% RR Foliar Fertilizer) & $13.27 \mathrm{c}$ \\
\hline T7(50\%rRR Organic Fertilizer +50\% Foliar Fertilizer) & $10.48 \mathrm{f}$ \\
\hline
\end{tabular}

${ }^{\text {a }}$ Average of three replications

In the same column, means followed by a common letter(s) are not significantly different at 5\% level by Tukey HSD test.

The result also agrees with the study of Masarirambi (2010) that commercial and subsistence farming has been and is still relying on the use of inorganic fertilizers for growing crops. In addition, Lian et al. (2017) found that the application of inorganic fertilizer improved the growth and development of crops faster than the application of organic fertilizers. 
Inorganic Fertilizers (Ground and Foliar Application) and Organic Fertilizer: Their Effects on the Growth and Yield of Pechay (Brassica napus L. subsp. chinensis var. Black Behi)

\subsubsection{Plant Height at 35 Days after Emergence (DAE)}

The data showed that the mean plant height of Pechay 35 DAE was significantly influenced by different types, levels, and methods of application of fertilizers (Table 4). $\mathrm{T}_{2}$ Plants (RR Inorganic Fertilizer (60-40-60 kg N, $\mathrm{P}_{2} \mathrm{O}_{5}, \mathrm{~K}_{2} \mathrm{O} / \mathrm{ha}$ )) remained significantly the tallest with a mean height of $14.39 \mathrm{~cm}$. While $\mathrm{T}_{1}$ (Control) plants also stayed the shortest with a mean height of $8.49 \mathrm{~cm}$. Results at $35 \mathrm{DAE}$ are consistent at 21 days after emergence. This means that Pechay plants even grown in pots under inorganic fertilizer are superior in height compared to organic and foliar fertilizer.

Table4. Tukey HSD (Effect of Different Fertilizer Types, Levels and Mode of Application on the Mean Plant Height of Pechay (cm) at 35 Days After Emergence (DAE) with Three Replications in RCBD)

\begin{tabular}{|l|c|}
\hline \multicolumn{1}{|c|}{ Treatments } & Mean Plant Height in cm \\
\hline T1(Control(Garden Soil)) & $8.50 \mathrm{~g}$ \\
\hline T2(RR Inorganic Fertilizer) & $14.39 \mathrm{a}$ \\
\hline T3(RR Organic Fertilizer) & $13.14 \mathrm{c}$ \\
\hline T4(RR Foliar Fertilizer) & $13.03 \mathrm{~d}$ \\
\hline T5(50\% RR Inorganic Fertilizer + 50\% RR Organic Fertilizer) & $11.84 \mathrm{e}$ \\
\hline T6(50\% RR Inorganic Fertilizer + 50\% RR Foliar Fertilizer) & $13.84 \mathrm{~b}$ \\
\hline T7(50\%rRR Organic Fertilizer +50\% Foliar Fertilizer) & $10.75 \mathrm{f}$ \\
\hline
\end{tabular}

a Average of three replications

In the same column, means followed by a common letter(s) are not significantly different at 5\% level by Tukey HSD test.

This result further agrees with Omidire et al.'s (2015) study on the "Impacts of Inorganic and Organic Fertilizer on Crop Performance Under a Microirrigation-Plastic Mulch Regime" which showed that the inorganic fertilizer had higher yields (lbs/acre) than organic fertilizer.

\subsubsection{Plant Height at 42 Days After Emergence (DAE)}

The study showed that the mean plant height of Pechay 42 DAE was significantly influenced by different types, levels, and methods of application of fertilizers (Table 5). As shown in Table 5, $\mathrm{T}_{2}$ plants (RR Inorganic Fertilizer (60-40-60 kg N, $\mathrm{P}_{2} \mathrm{O}_{5}, \mathrm{~K}_{2} \mathrm{O} / \mathrm{ha}$ )) stayed significantly the tallest with a mean height of $14.56 \mathrm{~cm}$. This was followed by $\mathrm{T}_{6}(50 \%$ RR Inorganic Fertilizer $+50 \%$ RR Foliar Fertilizer) andT 3 (RR Organic Fertilizer (30t/ha; 30g/pot)) andT 4 (RR Foliar Fertilizer (60ml/ 16 li $\left.\mathrm{H}_{2} \mathrm{O}\right)$ ); the latter two treatments being insignificantly different from each other having mean plant heights of 13.33 and $13.24 \mathrm{~cm}$ respectively. This shows that as far as plant height, $\mathrm{T}_{3}$ plants applied with organic fertilizers are performing at par with $\mathrm{T}_{4}$ plants applied with synthetic foliar fertilizer. The shortest plants were observed in $\mathrm{T}_{1}$ (Control) with a mean height of $8.66 \mathrm{~cm}$.

Table5. Tukey HSD (Effect of Different Fertilizer Types, Levels and Mode of Application on the Mean Plant Height of Pechay (cm) at 42 Days After Emergence (DAE) with Three Replications in RCBD)

\begin{tabular}{|l|c|}
\hline \multicolumn{1}{|c|}{ Treatments } & Mean Plant Height in cma \\
\hline T1(Control(Garden Soil)) & $8.66 \mathrm{f}$ \\
\hline T2(RR Inorganic Fertilizer) & $14.56 \mathrm{a}$ \\
\hline T3(RR Organic Fertilizer) & $13.33 \mathrm{c}$ \\
\hline T4(RR Foliar Fertilizer) & $13.24 \mathrm{c}$ \\
\hline T5(50\% RR Inorganic Fertilizer + 50\% RR Organic Fertilizer) & $11.90 \mathrm{~d}$ \\
\hline T6(50\% RR Inorganic Fertilizer + 50\% RR Foliar Fertilizer) & $13.74 \mathrm{~b}$ \\
\hline T7(50\%rRR Organic Fertilizer +50\% Foliar Fertilizer) & $10.95 \mathrm{e}$ \\
\hline
\end{tabular}

${ }^{a}$ Average of three replications

In the same column, means followed by a common letter(s) are not significantly different at 5\% level by Tukey HSD test.

Lian et al. (2017) support this result in that they found, inorganic fertilizer is a kind of fast and high nutrient chemicals. Moreover, Eifediyi and Remison's (2010) study on "The Effects of Inorganic Fertilizer on the Yield of Two Varieties of Cucumber (Cucumis sativus L.)" also conforms with this. They found that the growth and yield attributes of cucumber increased significantly with increase in inorganic fertilizer application. 
Inorganic Fertilizers (Ground and Foliar Application) and Organic Fertilizer: Their Effects on the Growth and Yield of Pechay (Brassica napus L. subsp. chinensis var. Black Behi)

These facts cause the farmers to use inorganic fertilizers. Studies by Pascual et al. (2013), pointed out that to produce high yield, most growers use synthetically-based products. Synthetically-based fertilizers are the most common fertilizers used by the farmers (Gonzales et al., 2015).

Result of the study showed $\mathrm{T}_{2}$ (RR Inorganic Fertilizer (60-40-60 kg N, $\mathrm{P}_{2} \mathrm{O}_{5}, \mathrm{~K}_{2} \mathrm{O} / \mathrm{ha}$ )) plants as the tallest, followed by $\mathrm{T}_{6}(50 \%$ RR Inorganic Fertilizer $+50 \%$ RR Foliar Fertilizer $)$ plants. $\mathrm{T}_{6}$ plants are nearly comparable with $\mathrm{T}_{2}$. This shows that foliar fertilizer is also a viable alternative in Pechay production. The results conform with Zaniewiez-Bajkowska et al.'s (2010) study on "The Yield Quality of Melon (Cucumis melo L.)" where foliar-fertilized plants deliver high yields of good quality at lower rates of mineral fertilization. In horticultural practice, foliar fertilization is also recommended as the most effective method of supplying plants with nutrients under deficiency conditions.

Rahman et al.'s (2015) study entitled "Foliar Feeding in Various Vegetables and Cereal Crops Boosting Growth and Yield Attributes" also agrees that $\mathrm{T}_{6}(50 \%$ RR Inorganic Fertilizer $+50 \%$ RR Foliar Fertilizer) is a viable alternative to $\mathrm{T}_{2}$ (RR Inorganic Fertilizer (60-40-60 kg N, $\mathrm{P}_{2} \mathrm{O}_{5}, \mathrm{~K}_{2} \mathrm{O} / \mathrm{ha}$ )). Results of their study showed that foliar application of macro and micro nutrients play an important role in the production of good crop and higher yield.

\subsubsection{Growth Rate}

Table 6 shows that the mean growth rate of Pechay 42 DAE was significantly influenced by different types, levels, and methods of application of fertilizers. It revealed that the highest growth rate of Pechay was observed in $\mathrm{T}_{2}$ (RR Inorganic Fertilizer (60-40-60 kg N, $\mathrm{P}_{2} \mathrm{O}_{5}, \mathrm{~K}_{2} \mathrm{O} / \mathrm{ha}$ )) with the mean growth rate of $3.015 \mathrm{~mm}$ per day. The shortest growth rate was observed in $\mathrm{T}_{7}$ (50\% RR Organic Fertilizer (15t/ha; $15 \mathrm{~g} / \mathrm{pot})+50 \%$ RR Foliar Fertilizer $\left.\left(30 \mathrm{ml} / 16 \mathrm{li}_{2} \mathrm{O}\right)\right)$ with the mean value of 1.237 $\mathrm{mm}$ per day. Moreover, Table 6 showed that $\mathrm{T}_{2}$ is significantly different from all other treatments.

Table 6. Tukey HSD (Effect of Different Fertilizer Types, Levels and Mode of Application on the Growth Rate of Pechay (mm/day) from Day 14 to 42 Days After Emergence (DAE) with Three Replications in RCBD)

\begin{tabular}{|l|c|}
\hline \multicolumn{1}{|c|}{ Treatments } & Mean Growth Rate $\mathbf{~ m m} / \mathbf{d a y}^{\mathbf{a}}$ \\
\hline T1(Control(Garden Soil)) & $1.988 \mathrm{c}$ \\
\hline T2(RR Inorganic Fertilizer) & $3.015 \mathrm{a}$ \\
\hline T3(RR Organic Fertilizer) & $1.863 \mathrm{c}$ \\
\hline T4(RR Foliar Fertilizer) & $2.216 \mathrm{bc}$ \\
\hline T5(50\% RR Inorganic Fertilizer + 50\% RR Organic Fertilizer) & $1.811 \mathrm{c}$ \\
\hline T6(50\% RR Inorganic Fertilizer + 50\% RR Foliar Fertilizer) & $2.493 \mathrm{~b}$ \\
\hline T7(50\%rRR Organic Fertilizer +50\% Foliar Fertilizer) & $1.237 \mathrm{~d}$ \\
\hline
\end{tabular}

a Average of three replications

In the same column, means followed by a common letter(s) are not significantly different at $5 \%$ level by Tukey HSD test.

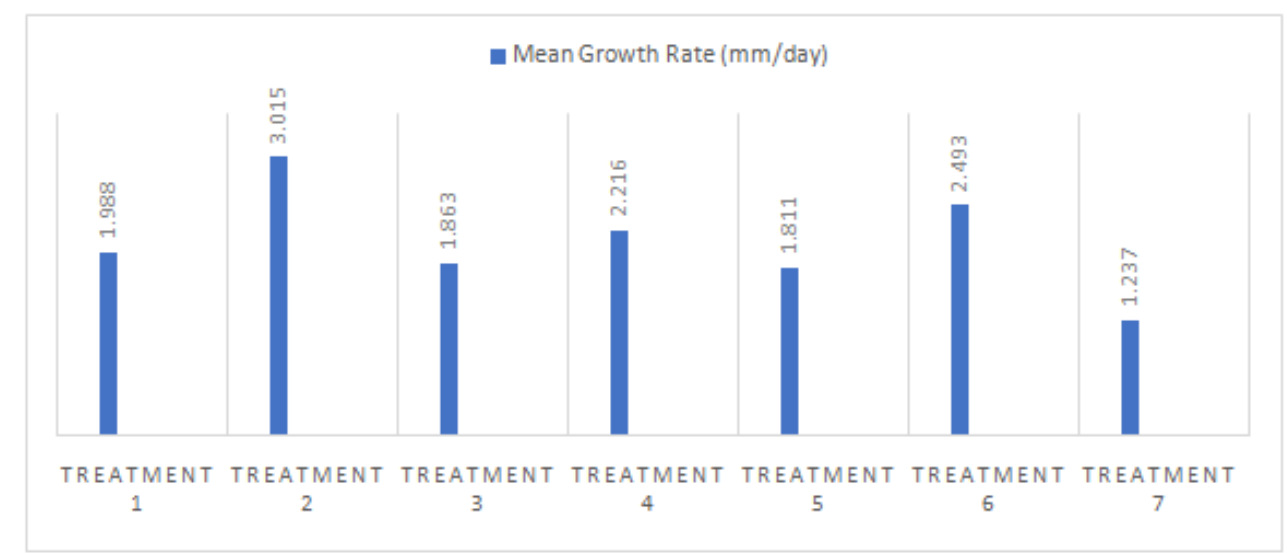

Figure2. Effect of the Different Fertilizer Types, Levels and Mode of Application on the Mean Growth Rate of Pechay from 14 to 42 Days After Emergence (DAE)

Masarirambi (2010) pointed out that commercial and subsistence farming has been and is still relying on the use of inorganic fertilizers for growing crops. This is because they are easy to use, quickly absorbed and utilized by crops. This, therefore, proves that the application of inorganic fertilizer yields higher than organic fertilizer. In addition, Omidire et al. (2015) showed that inorganic fertilizer 
had higher yields (lbs/acre) than organic fertilizer. Lian et al. (2017) also revealed that inorganic fertilizer is a kind of fast and high nutrient chemicals.

Nurhidayatia et al. (2016) studied the yield and quality of cabbage (Brassica oleracea L.var. capitata) under organic growing media using vermicompost and earthworm Pontoscolex corethrurus inoculation contradicts to the result of the study. Results revealed that the application of vermicompost combined with inoculation of earthworm $P$. corethrurus significantly increased total biomass, marketable weight, crop diameter, and harvest index compared with the cabbage grown in inorganic media. However, Ahirwar and Hussain's (2015) study on the effect of vermicompost on growth, yield, and quality of vegetable crops contradicts to the result of the present study. They found that the application of vermicompost positively affected the growth of vegetable transplants, perhaps by altering the nutritional balance of the medium. Transplant quality was improved in peppers and eggplants while tomato transplant quality was slightly reduced. Further, there were no significant differences in field performance. Hence, vermicomposting is a sustainable technique for solid waste disposal.

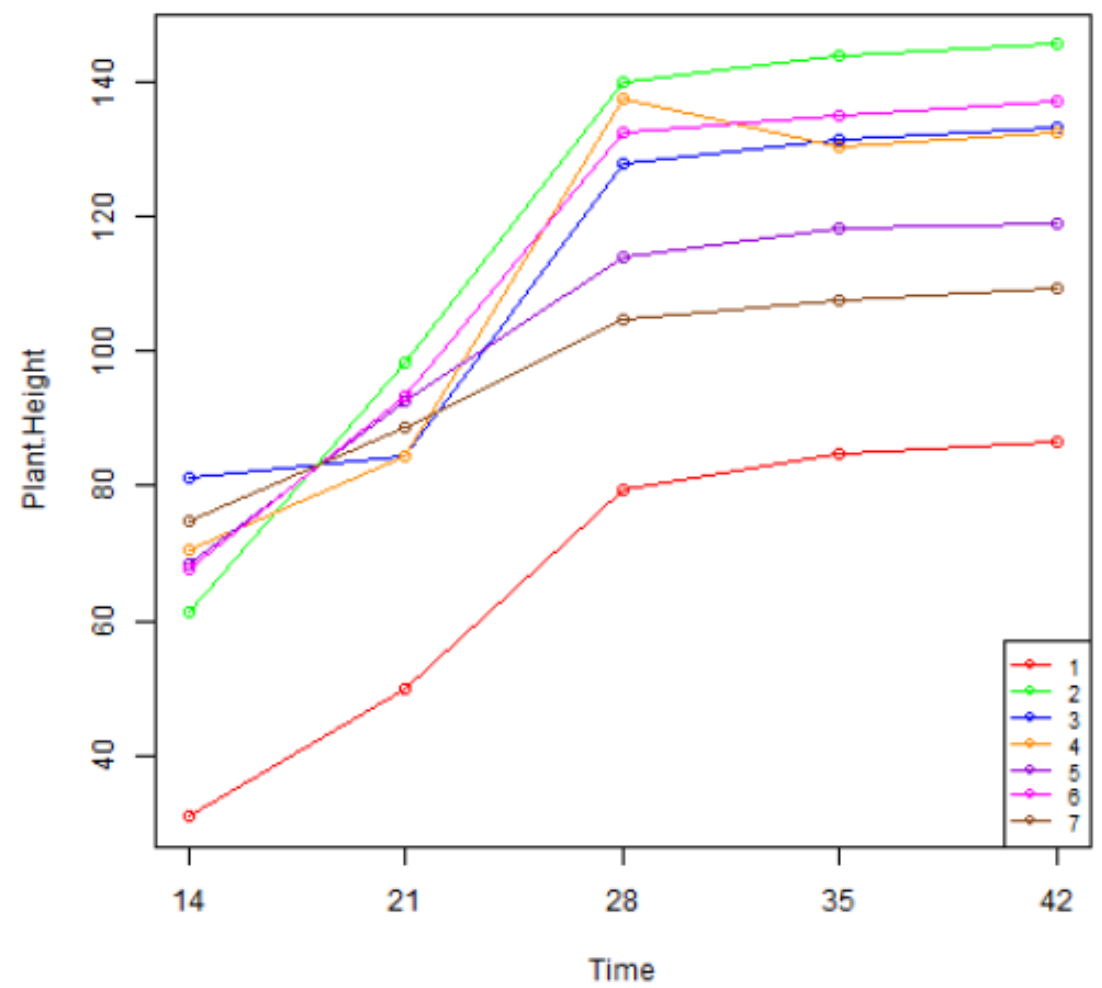

Figure3. Effect of the Different Fertilizer Types, Levels and Mode of Application on the Mean Plant Height of Pechay from 14 to 42 Days After Emergence (DAE)

Legend:

Red: $T_{1}$ Control (garden soil)

Green: $T_{2}$ RR Inorganic Fertilizer

Blue: $T_{3}$ RR Organic Fertilizer (30t/ha; 30g/pot)

Yellow: $T_{4}$ RR Foliar Fertilizer

Violet: $T_{5} 50 \%$ RR Inorganic Fertilizer $+50 \%$ RR Organic Fertilizer

Lavender: $T_{6} 50 \%$ RR Inorganic Fertilizer $+50 \%$ Foliar Fertilizer

Brown: $T_{7} 50 \%$ Organic Fertilizer $+50 \%$ Foliar Fertilizer 
Inorganic Fertilizers (Ground and Foliar Application) and Organic Fertilizer: Their Effects on the Growth and Yield of Pechay (Brassica napus L. subsp. chinensis var. Black Behi)

\subsubsection{Number of Leaves}

\subsubsection{Number of Leaves at 14 Days After Emergence (DAE)}

Table 7 shows that the mean number of leaves 14 DAE was significantly influenced by different types, levels, and methods of application of fertilizers. The highest number of leaves was observed inT $_{3}$ (RR Organic Fertilizer (30t/ha; 30g/pot)) which was significantly different from the rest except $\mathrm{T}_{7}$ (50\% RR Organic Fertilizer (15t/ha; $15 \mathrm{~g} /$ pot $)+50 \%$ RR Foliar Fertilizer $\left(30 \mathrm{ml} / 16 \mathrm{li} \mathrm{H}_{2} \mathrm{O}\right)$ ) with a mean of 4.267 and3.900 respectively. The least number of leaves was observed in $\mathrm{T}_{1}$ (Control) with a mean value of 2.953. (30 ml/ $\left.16 \mathrm{li}_{2} \mathrm{O}\right)$ ) but significantly different from all other treatments.

Table7. Tukey HSD (Effect of Different Fertilizer Types, Levels and Mode of Application on the Number of Leaves of Pechay at 14 Days After Emergence (DAE) with Three Replications in RCBD)

\begin{tabular}{|l|c|}
\hline \multicolumn{1}{|c|}{ Treatments } & Mean Number of Leaves $^{\text {a }}$ \\
\hline T1(Control(Garden Soil)) & $2.953 \mathrm{~d}$ \\
\hline T2(RR Inorganic Fertilizer) & $3.553 \mathrm{bc}$ \\
\hline T3(RR Organic Fertilizer) & $4.267 \mathrm{a}$ \\
\hline T4(RR Foliar Fertilizer) & $3.490 \mathrm{bc}$ \\
\hline T5(50\% RR Inorganic Fertilizer + 50\% RR Organic Fertilizer) & $3.623 \mathrm{bc}$ \\
\hline T6(50\% RR Inorganic Fertilizer + 50\% RR Foliar Fertilizer) & $3.290 \mathrm{~cd}$ \\
\hline T7(50\%rRR Organic Fertilizer +50\% Foliar Fertilizer) & $3.900 \mathrm{ab}$ \\
\hline
\end{tabular}

a Average of three replications

In the same column, means followed by a common letter(s) are not significantly different at 5\% level by Tukey HSD test.

The results conform with the findings of Kaur et al. (2015) in their study "The Effect of Vermicompost and Vermiwash on Growth of Vegetables". They found that organic waste material processed by the naturally occurring earthworm was used to produce vermicompost which supplies nutrients and other soil stimulants for plant growth and improve soil quality. Another study by Arancon and Edwards (2005) supports the result of this study where vermicompost used at lower substitution rates, increases growth, flowering and yields of vegetable and ornamental crops.

\subsubsection{Number of Leaves at 21 Days after Emergence (DAE)}

Table 8 shows that the mean number of leaves of plants 21 DAE was to some extent significantly influenced by different types, levels, and methods of application of fertilizers. Table 8 shows that the highest number of leaves was observed in $_{3}$ (RR Organic Fertilizer (30t/ha; 30g/pot)) with a mean of 6.930. Coming second is $\mathrm{T}_{6}$ (50\% RR Inorganic Fertilizer (30-20-30 kg N, $\left.\mathrm{P}_{2} \mathrm{O}_{5}, \mathrm{~K}_{2} \mathrm{O} / \mathrm{ha}\right)+50 \% \mathrm{RR}$ Foliar Fertilizer $\left(30 \mathrm{ml} / 16 \mathrm{li}_{2} \mathrm{O}\right)$ ) and then third is $\mathrm{T}_{4}\left(\mathrm{RR}\right.$ Foliar Fertilizer $\left(60 \mathrm{ml} / 16 \mathrm{li} \mathrm{H}_{2} \mathrm{O}\right)$ ), $\mathrm{T}_{5}$ (50\% RR Inorganic Fertilizer (30-20-30 kg N, $\left.\mathrm{P}_{2} \mathrm{O}_{5}, \mathrm{~K}_{2} \mathrm{O} / \mathrm{ha}\right)+50 \%$ RR Organic Fertilizer (15t/ha; $15 \mathrm{~g} /$ pot $)$ ) and $\mathrm{T}_{7}(50 \%$ RR Organic Fertilizer (15t/ha; 15g/pot) + 50\% RR Foliar Fertilizer (30ml/ 16 li $\left.\mathrm{H}_{2} \mathrm{O}\right)$ ). The least number of leaves was observed in $\mathrm{T}_{1}$ (Control) with the mean value of4.113. Moreover, $\mathrm{T}_{3}$ (RR Organic Fertilizer (30t/ha; 30g/pot)) is significantly different from all other treatments.

Table8. Tukey HSD (Effect of Different Fertilizer Types, Levels and Mode of Application on the Number of Leaves of Pechay at 21 Days After Emergence (DAE) with Three Replications in RCBD)

\begin{tabular}{|l|c|}
\hline \multicolumn{1}{|c|}{ Treatments } & Mean Number of Leaves \\
\hline T1(Control(Garden Soil)) & $4.113 \mathrm{~d}$ \\
\hline T2(RR Inorganic Fertilizer) & $5.490 \mathrm{c}$ \\
\hline T3(RR Organic Fertilizer) & $6.930 \mathrm{a}$ \\
\hline T4(RR Foliar Fertilizer) & $5.510 \mathrm{c}$ \\
\hline T5(50\% RR Inorganic Fertilizer + 50\% RR Organic Fertilizer) & $5.623 \mathrm{c}$ \\
\hline T6(50\% RR Inorganic Fertilizer + 50\% RR Foliar Fertilizer) & $6.290 \mathrm{~b}$ \\
\hline T7(50\%rRR Organic Fertilizer +50\% Foliar Fertilizer) & $5.510 \mathrm{c}$ \\
\hline
\end{tabular}

a Average of three replications

In the same column, means followed by a common letter(s) are not significantly different at 5\% level by Tukey HSD test.

The result of the study agrees with Bercero et al. (2014) who pointed out that the application of $T$. harzianum $+E$. fetida compost produced comparable results as to the number of leaves, leaf width, leaf length, fresh weight and dry weight with the positive control (inorganic fertilizer (Urea) at 0.65 
Inorganic Fertilizers (Ground and Foliar Application) and Organic Fertilizer: Their Effects on the Growth and Yield of Pechay (Brassica napus L. subsp. chinensis var. Black Behi)

grams' plant-1) indicating that it is a good alternative to application of inorganic fertilizer to the growth of Pechay. Compost derived from the application of T. harzianum + Vermi worms is highly recommended to produce Pechay.

\subsubsection{Number of Leaves at 28 Days After Emergence (DAE)}

Table 9 shows that the mean number of leaves of plants 28 DAE was not significantly influenced by different types, levels, and methods of application of fertilizers. Table 9 shows that all treated plants $\left(\mathrm{T}_{2}-\mathrm{T}_{7}\right)$ are not significantly different from each other which shows that the number of leaves is not affected by the different types, levels, and methods of fertilizer application.

Table9. Tukey HSD (Effect of Different Fertilizer Types, Levels and Mode of Application on the Number of Leaves of Pechay at 28 Days After Emergence (DAE) with Three Replications in RCBD)

\begin{tabular}{|l|c|}
\hline \multicolumn{1}{|c|}{ Treatments } & Mean Number of Leaves $^{\mathbf{a}}$ \\
\hline T1(Control [Garden Soil]) & $5.490 \mathrm{~b}$ \\
\hline T2(RR Inorganic Fertilizer) & $7.133 \mathrm{a}$ \\
\hline T3(RR Organic Fertilizer) & $7.890 \mathrm{a}$ \\
\hline T4(RR Foliar Fertilizer) & $8.087 \mathrm{a}$ \\
\hline T5(50\% RR Inorganic Fertilizer + 50\% RR Organic Fertilizer) & $8.023 \mathrm{a}$ \\
\hline T6(50\% RR Inorganic Fertilizer + 50\% RR Foliar Fertilizer) & $7.290 \mathrm{a}$ \\
\hline T7(50\%rRR Organic Fertilizer +50\% Foliar Fertilizer) & $7.510 \mathrm{a}$ \\
\hline
\end{tabular}

${ }^{a}$ Average of three replications

In the same column, means followed by a common letter(s) are not significantly different at 5\% level by Tukey HSD test.

\subsubsection{Number of Leaves at 35 Days After Emergence (DAE)}

Table 10 shows that the mean number of leaves 35 DAE was significantly influenced by different types, levels, and methods of application of fertilizers. As shown, the highest number of leaves of plant was observed in $\mathrm{T}_{5}\left(50 \%\right.$ RR Inorganic Fertilizer (30-20-30 kg N, $\left.\mathrm{P}_{2} \mathrm{O}_{5}, \mathrm{~K}_{2} \mathrm{O} / \mathrm{ha}\right)+50 \% \mathrm{RR}$ Organic Fertilizer (15t/ha; $15 \mathrm{~g} / \mathrm{pot}))$ with a mean leaf number of 9.847 . The least number of leaves was observed in $\mathrm{T}_{1}$ (Control) with a mean value of6.490. Moreover, while $\mathrm{T}_{5}$ is significantly different from all other treatments, all $\mathrm{T}_{2}, \mathrm{~T}_{3}, \mathrm{~T}_{4}, \mathrm{~T}_{6}$ and $\mathrm{T}_{7}$ are not significantly different from one another. Again, this may confirm an earlier finding of this study that the number of leaves is not significantly affected by the different types, levels, and methods of fertilizer application. This is also seen in Table 11 where practically all plants receiving fertilizers $\left(T_{2}-T_{7}\right)$ except $\left(T_{6}\right)$ are not significantly different from one another in terms of the number of leaves.

Table10. Tukey HSD (Effect of Different Fertilizer Types, Levels and Mode of Application on the Number of Leaves of Pechay at 35 Days After Emergence (DAE) with Three Replications in RCBD)

\begin{tabular}{|l|c|}
\hline \multicolumn{1}{|c|}{ Treatments } & Mean Number of Leaves $^{\mathbf{a}}$ \\
\hline T1(Control [Garden Soil]) & $6.490 \mathrm{c}$ \\
\hline T2(RR Inorganic Fertilizer) & $8.290 \mathrm{~b}$ \\
\hline T3(RR Organic Fertilizer) & $8.667 \mathrm{~b}$ \\
\hline T4(RR Foliar Fertilizer) & $8.433 \mathrm{~b}$ \\
\hline T5(50\% RR Inorganic Fertilizer + 50\% RR Organic Fertilizer) & $9.847 \mathrm{a}$ \\
\hline T6(50\% RR Inorganic Fertilizer + 50\% RR Foliar Fertilizer) & $8.290 \mathrm{~b}$ \\
\hline T7(50\%rRR Organic Fertilizer +50\% Foliar Fertilizer) & $8.513 \mathrm{~b}$ \\
\hline
\end{tabular}

a Average of three replications

In the same column, means followed by a common letter(s) are not significantly different at 5\% level by Tukey HSD test.

\subsubsection{Number of Leaves at 42 Days after Emergence (DAE)}

Table 11 shows that the mean number of leaves 42 DAE was to a great extent not significantly influenced by the different types, levels, and methods of application of fertilizers. As shown, the highest number of leaves was observed in $\mathrm{T}_{5}$ (50\% RR Inorganic Fertilizer (30-20-30 kg N, $\mathrm{P}_{2} \mathrm{O}_{5}$, $\left.\mathrm{K}_{2} \mathrm{O} / \mathrm{ha}\right)+50 \%$ RR Organic Fertilizer (15t/ha; $\left.15 \mathrm{~g} / \mathrm{pot}\right)$ ) with a mean of 10.197 . The least number of leaves was observed in $\mathrm{T}_{1}$ (Control (garden soil)) with a mean value of 6.867. However, no significant differences can be seen between and among the fertilizer treated plants as to number of leaves. This again leads to an earlier observation (since at $28 \mathrm{DAE}$ ) that the different types, levels, and methods of 
Inorganic Fertilizers (Ground and Foliar Application) and Organic Fertilizer: Their Effects on the Growth and Yield of Pechay (Brassica napus L. subsp. chinensis var. Black Behi)

application did not affect the total number of leaves. This contradicts the results obtained by Ogundare et al. (2015) where plant height, leaf numbers, branch number, and fruit number per plant of tomato among others were significantly affected by the combined use of organic and inorganic fertilizers.

Table11. Tukey HSD (Effect of Different Fertilizer Types, Levels and Mode of Application on the Number of Leaves of Pechay at 42 Days After Emergence (DAE) with Three Replications in RCBD)

\begin{tabular}{|l|c|}
\hline \multicolumn{1}{|c|}{ Treatments } & Mean Number of Leaves $^{\mathbf{a}}$ \\
\hline T1(Control(Garden Soil)) & $6.867 \mathrm{~b}$ \\
\hline T2(RR Inorganic Fertilizer) & $8.800 \mathrm{a}$ \\
\hline T3(RR Organic Fertilizer) & $8.953 \mathrm{a}$ \\
\hline T4(RR Foliar Fertilizer) & $8.897 \mathrm{a}$ \\
\hline T5(50\% RR Inorganic Fertilizer + 50\% RR Organic Fertilizer) & $10.197 \mathrm{a}$ \\
\hline T6(50\% RR Inorganic Fertilizer + 50\% RR Foliar Fertilizer) & $8.580 \mathrm{ab}$ \\
\hline T7(50\%rRR Organic Fertilizer +50\% Foliar Fertilizer) & $8.917 \mathrm{a}$ \\
\hline
\end{tabular}

a Average of three replications

In the same column, means followed by a common letter(s) are not significantly different at $5 \%$ level by Tukey HSD test.

\subsection{Yield Components (Weight of Marketable Plant [in g])}

Table 12 shows that the different types, levels, and methods of fertilizer application used had highly significant influence on the total weight of the plants. As shown in Table 12, $\mathrm{T}_{2}(\mathrm{Rec}$. Rate (RR) Inorganic Fertilizer (60-40-60 kg N, $\mathrm{P}_{2} \mathrm{O}_{5}, \mathrm{~K}_{2} \mathrm{O} / \mathrm{ha}$ )) came out the highest in total weight or yield with a mean of 225.863. this was subsequently followed by $\mathrm{T}_{6}(50 \% \mathrm{RR}$ Inorganic Fertilizer (30-20-30 kg N, $\left.\mathrm{P}_{2} \mathrm{O}_{5}, \mathrm{~K}_{2} \mathrm{O} / \mathrm{ha}\right)+50 \%$ RR Foliar Fertilizer (30ml/ $16 \mathrm{li}$ $\left.\mathrm{H}_{2} \mathrm{O}\right)$ ), $\mathrm{T}_{3}(\mathrm{RR}$ Organic Fertilizer $(30 \mathrm{t} / \mathrm{ha} ; 30 \mathrm{~g} / \mathrm{pot})), \mathrm{T}_{4}$ (RR Foliar Fertilizer $(60 \mathrm{ml} / 16 \mathrm{li}$ $\left.\mathrm{H}_{2} \mathrm{O}\right)$ ), $\mathrm{T}_{7}(50 \%$ RR Organic Fertilizer (15t/ha; 15g/pot) + 50\% RR Foliar Fertilizer (30ml/ 16 li $\left.\mathrm{H}_{2} \mathrm{O}\right)$ ) and $\mathrm{T}_{5}\left(50 \%\right.$ RR Inorganic Fertilizer (30-20-30 kg N, $\left.\mathrm{P}_{2} \mathrm{O}_{5}, \mathrm{~K}_{2} \mathrm{O} / \mathrm{ha}\right)+50 \% \mathrm{RR}$ Organic Fertilizer (15t/ha; 15g/pot)) with mean weights of $201.503 \mathrm{~g}, 187.290 \mathrm{~g}, 185.580 \mathrm{~g}$, $164.203 \mathrm{~g}$, and $154.557 \mathrm{~g}$, respectively.

Table12. Tukey HSD (Effect of Different Fertilizer Types, Levels and Methods of Application on the Mean Weight of Marketable Pechay in Grams with Three Replications in RCBD)

\begin{tabular}{|c|c|}
\hline Treatments & Mean Weight in grama \\
\hline T1(Control [Garden Soil]) & - \\
\hline T2(RR Inorganic Fertilizer) & $225.863 a$ \\
\hline T3(RR Organic Fertilizer) & $187.290 \mathrm{c}$ \\
\hline T4(RR Foliar Fertilizer) & $185.580 \mathrm{~d}$ \\
\hline T5(50\% RR Inorganic Fertilizer + 50\% RR Organic Fertilizer) & $154.557 \mathrm{f}$ \\
\hline T6(50\% RR Inorganic Fertilizer + 50\% RR Foliar Fertilizer) & $201.503 b$ \\
\hline T7(50\%rRR Organic Fertilizer $+50 \%$ Foliar Fertilizer) & $164.203 \mathrm{e}$ \\
\hline
\end{tabular}

a Average of three replications

In the same column, means followed by a common letter(s) are not significantly different at $5 \%$ level by Tukey HSD test.

${ }^{\mathrm{ns}}=$ not significant

** $=$ significant at $\alpha=0.01$

$\mathrm{cv}=0.15 \%$

The result of the study conforms with the study by Eifediyi and Remison (2010) which showed that fruit number per plant and total yield including the vegetative parameter increased significantly $(\mathrm{P}<$ $0.05)$ with the increase in inorganic fertilizer application up to the highest level. In this study, the two highest marketable weights were $\mathrm{T}_{2}$ (Rec. Rate (RR) Inorganic Fertilizer (60-40-60 kg N, $\mathrm{P}_{2} \mathrm{O}_{5}$, $\left.\mathrm{K}_{2} \mathrm{O} / \mathrm{ha}\right)$ ) and $\mathrm{T}_{6}\left(50 \%\right.$ RR Inorganic Fertilizer (30-20-30 kg N, $\left.\mathrm{P}_{2} \mathrm{O}_{5}, \mathrm{~K}_{2} \mathrm{O} / \mathrm{ha}\right)+50 \%$ RR Foliar Fertilizer (30ml/ 16 li $\left.\mathrm{H}_{2} \mathrm{O}\right)$ ); both commercial inorganic fertilizers, although half of the fertilizer applied in $\mathrm{T}_{6}$ was foliar. Zaniewiez-Bajkowska et al. (2010) cite that in horticultural practice, foliar fertilization is also recommended as the most effective method of supplying plants with nutrients under deficiency conditions. 
Inorganic Fertilizers (Ground and Foliar Application) and Organic Fertilizer: Their Effects on the Growth and Yield of Pechay (Brassica napus L. subsp. chinensis var. Black Behi)

\section{CONCLUSION}

First, the use of all inorganic fertilizer $\left(\mathrm{T}_{2}\right.$ and $\left.\mathrm{T}_{6}\right)$, in Pechay production either applied on the ground or foliar is more effective in terms of total marketable weight or yield. Moreover, it can be said that as far as this study the different types, levels and methods of fertilizer application only had significant results or differences between treatments on the plant height and marketable weight parameters, not on the number of leaves for the most part.

Second, as far as plant height and marketable weight, $\mathrm{T}_{3}$ (RR Organic Fertilizer (30t/ha; 30g/pot)) came a close third after $\mathrm{T}_{2}$ (Rec. Rate (RR) Inorganic Fertilizer (60-40-60 kg N, $\mathrm{P}_{2} \mathrm{O}_{5}, \mathrm{~K} 2 \mathrm{O} / \mathrm{ha}$ )) and $\mathrm{T}_{6}$ (50\% RR Inorganic Fertilizer (30-20-30 kg N, P2O5, K2O/ha) + 50\% RR Foliar Fertilizer (30ml/ 16 li $\mathrm{H} 2 \mathrm{O})$ ). In addition, $\mathrm{T}_{3}$ topped the sales due to much lower production cost, the use of all organic fertilizer (in this case, vermicompost) is a very viable alternative to higher and more profitable Pechay production which is safe for human consumption.

\section{RECOMMENDATIONS}

Based on the results and conclusions of this study, the use of organic fertilizers is therefore highly recommended. This will foster the conversion of biodegradable farm wastes to inexpensive organic fertilizers and produce vegetables that are safe for human consumption.

In areas where land area is a problem, this study showed that the use of pots can be a viable alternative to increase vegetable production and provide food in urban settings. Moreover, the result of the study is recommended for dissemination to the Department of Agriculture (DA) to guide the farmers to use safe fertilizer options. Further studies on Pechay production is recommended especially on the use of different organic fertilizer sources and the foliar method of fertilizer application.

\section{REFERENCES}

[1] Acero, L. H. (2013). Growth Response of Brassica rapa on the Different Wavelength of Light. International Journal of Chemical Engineering and Applications, 4(6), 415-418.

[2] Ahirwar, C. S., \& Hussain, A. (2015). Effect of vermicompost on growth, yield and quality of vegetable crops. International Journal of Applied and Pure Science and Agriculture, 1(8), 49-56.

[3] Aira, M., Monroy, F., \& Domínguez, J. (2007). Earthworms strongly modify microbial biomass and activity triggering enzymatic activities during vermicomposting independently of the application rates of pig slurry. Science of the total Environment, 385(1-3), 252-261.

[4] Alkurd, A., Takruri, H. R., \& Al-Sayyed, H. (2008). Tannin contents of selected plants used in Jordan. Jordan Journal of Agricultural Sciences, 4(3), 265-274.

[5] Arancon, N. Q., \& Edwards, C. A. (2005). Effects of vermicomposts on plant growth. Soil Ecology Laboratory, The Ohio State University, Columbus, OH, 43210, 16-18.

[6] Arancon, N. Q., Edwards, C. A., Bierman, P., Welch, C., \& Metzger, J. D. (2004). Influences of vermicomposts on field strawberries: 1. Effects on growth and yields. Bioresource technology, 93(2), 145153.

[7] Atiyeh, R. M., Subler, S., Edwards, C. A., Bachman, G., Metzger, J. D., \& Shuster, W. (2000). Effects of vermicomposts and composts on plant growth in horticultural container media and soil. Pedobiologia, 44(5), 579-590.

[8] Bercero D. II M., Aranico E. C., Tabaranza A. C. E., Amparado Jr. R. F., 2014 Growth performance of pechay (Brassica rapa) in household derived composts. AAB Bioflux, 6(3), 169-175.

[9] Buckerfield, J., \& Webster, K. (1998). Worm-worked waste boosts grape yields. Australian and New Zealand Wine Industry Journal, 13, 73-80.

[10] Buckman, H. O., \& Brady, N. C. (1974). The Nature and Properties of Soil. Mc Millan Pub. Inc. New York. 639p.

[11] Chaurasia, S. N. S., Singh, K. P., \& Rai, M. (2005). Effect of foliar application of water-soluble fertilizers on growth, yield and quality of tomato (Lycopersicon esculentum L.). Sri Lankan J. Agric. Sci, 42, 66-70.

[12] Chung, K. T., Lu, Z., \& Chou, M. W. (1998). Mechanism of inhibition of tannic acid and related compounds on the growth of intestinal bacteria. Food and Chemical Toxicology, 36(12), 1053-1060.

[13] Dalal, L. P., Mishra, A., \& Dhabarde, P. (2014). Growth Yield and Quality of Vegetables under Chemical and Organic Farming. International Journal of Scientific \& Engineering Research, 5(3). https://www.ijser.org/paper/Growth-Yield-and-Quality-of-Vegetables-under-Chemical.html 
Inorganic Fertilizers (Ground and Foliar Application) and Organic Fertilizer: Their Effects on the Growth and Yield of Pechay (Brassica napus L. subsp. chinensis var. Black Behi)

[14] Domínguez, J., \& Gómez-Brandón, M. (2012). Vermicomposting: composting with earthworms to recycle organic wastes. Mangagemnet of organic waste. Rijeka, Croatia: In Tech, 29-48.

[15] Eifediyi, E. K., \& Remison, S. U. (2010). Growth and yield of cucumber (Cucumis sativus L.) as influenced by farmyard manure and inorganic fertilizer. Journal of Plant Breeding and Crop Science, 2(7), 216-220.

[16] Eroy, M. (2015). Yield of Pechay (Brassica napus L. var. Black Behi) as Influenced by the Application of Full on Liquid Fertilizer. Bureau of Agriculture and Fisheries Standards. Terminal Report EUP No. 012. https://dokumen.tips/documents/yield-of-pechay-brassica-napus-l-var-black-behi-as-productionhowever.html

[17] Fernández, V., \& Brown, P. H. (2013). From plant surface to plant metabolism: the uncertain fate of foliarapplied nutrients. Frontiers in plant science, 4, 289.

[18] Gonzales, L. M. R., Caralde, R. A., \& Aban, M. L. (2015). Response of Pechay (Brassica napus L.) to different levels of compost fertilizer. International Journal of Scientific and Research Publications, 5(2), $1-4$.

[19] Grappelli, A., Tomati, U., Galli, E., \& Vergari, B. (1985). Earthworm casting in plant propagation. HortScience, 20(5), 874-876.

[20] Hagerman, A. E., Robbins, C. T., Weerasuriya, Y., Wilson, T. C., \& McArthur, C. (1992). Tannin chemistry in relation to digestion. Rangeland Ecology \& Management/Journal of Range Management Archives, 45(1), 57-62.

[21] Handreck, K. A. (1986). Vermicomposts as components of potting media. Biocycle, 27(9), 58-62.

[22] Hindell, R. P., McKenzie, B. M., \& Tisdall, J. M. (1997). Influence of drying and ageing on the stabilization of earthworm (Lumbricidae) casts. Biology and fertility of soils, 25(1), 27-35.

[23] Johnson, R. S., Rosecrance, R., Weinbaum, S., Andris, H., \& Wang, J. (2001). Can we approach complete dependence on foliar-applied urea nitrogen in an early-maturing peach?. Journal of the American Society for Horticultural Science, 126(3), 364-370.

[24] Kaur, P., Bhardwaj, M. and Babbar, I. (2015). Effect of vermicompost and vermiwash on growth of vegetables. Research Journal of Animal, Veterinary and Fishery Sciences, 3(4), 9-12.

[25] Kerin, V., \& Berova, M. (2003). Foliar fertilization in plants. Videnov \& Son, Sofia.

[26] Kuepper, G. (2003). Foliar fertilization. NCAT Agriculture Specialist. ATTRA Publication\# CT13.

[27] Lian, H., Ouyang, L., Liu, J., Yang, L. \& Zou, P. (2017). Effects of different proportions of inorganic fertilizer and organic fertilizer on yield and quality of amaranth. Proceedings of the 2017 6th International Conference on Energy, Environment and Sustainable Development. Advances in Engineering Research, 129, 911-915. https://doi.org/10.2991/iceesd-17.2017.166

[28] Lim, A. H., \& Vimala, P. (2012). Growth and yield responses of four leafy vegetables to organic fertilizer. Journal of Tropical Agriculture and Food Science, 40(1), 1-11.

[29] Mandić, V., Simić, A., Krnjaja, V., Bijelić, Z., Tomić, Z., Stanojković, A., \& Ruzić-Muslić, D. (2015). Effect of foliar fertilization on soybean grain yield. Biotechnology in Animal Husbandry, 31(1), 133-143.

[30] Masarirambi, M. T., Hlawe, M. M., Oseni, O. T., \& Sibiya, T. E. (2010). Effects of organic fertilizers on growth, yield, quality and sensory evaluation of red lettuce (Lactuca sativa L.)'Veneza Roxa'. Agriculture and Biology Journal of North America, 1(6), 1319-1324.

[31] Mueller-Harvey, I. (2006). Unravelling the conundrum of tannins in animal nutrition and health. Journal of the Science of Food and Agriculture, 86(13), 2010-2037.

[32] Natsheh, B., \& Mousa, S. (2014). Effect of organic and inorganic fertilizers application on soil and Cucumber (Cucumis Sativa L.) plant productivity. Int. J. Agric. For, 4, 166-170.

[33] Nurhidayati, U. A., Ali, U., \& Murwani, I. (2016). Yield and quality of cabbage (Brassica oleracea L. var. Capitata) under organic growing media using vermicompost and earthworm Pontoscolex corethrurus inoculation. Agriculture and Agricultural Science Procedia, 11(2016), 5-13.

[34] Ogundare, S. K., Babalola, T. S., Hinmikaiye, A. S., \& Oloniruha, J. A. (2015). Growth and fruit yield of tomato as influenced by combined use of organic and inorganic fertilizer in Kabba, Nigeria. European Journal of Agriculture and Forestry Research, 3(3), 48-56.

[35] Omidire, N. S., Shange, R., Khan, V., Bean, R., \& Bean, J. (2015). Assessing the impacts of inorganic and organic fertilizer on crop performance under a microirrigation-plastic mulch regime. Professional Agricultural Workers Journal (PAWJ), 3(174-2016-2179).

[36] Parle, J. N. (1963). A microbiological study of earthworm casts. Microbiology, 31(1), 13-22. 
Inorganic Fertilizers (Ground and Foliar Application) and Organic Fertilizer: Their Effects on the Growth and Yield of Pechay (Brassica napus L. subsp. chinensis var. Black Behi)

[37] Pascual, P. R., Jarwar, A. D., \& Nitural, P. S. (2013). Fertilizer, fermented activators, and EM utilization in pechay (Brassica pekinensis L.) production. Pakistan Journal of Agriculture, Agricultural Engineering and Veterinary Sciences, 29(1), 56-69.

[38] Prado, A. J., \& Sampaga, L. O. (2013). Response of pechay, (Brassica rapa) to organic fertilizer under DMMMSU-NLUC condition, La Union, Philippines. Undergraduate thesis of Don Mariano Marcos Memorial State University.

[39] Rahman, I. U., Afzal, A., Iqbal, Z., Shah, A. H., Khan, M. A., Ijaz, F., .. \& Manan, S. (2015). Review of foliar feeding in various vegetables and cereal crops boosting growth and yield attributes. AmericanEurasian Journal of Agricultural and Environmental Sciences, 15, 74-77.

[40] Tejada, M., Gómez, I., Hernández, T., \& García, C. (2010). Utilization of vermicomposts in soil restoration: effects on soil biological properties. Soil Science Society of America Journal, 74(2), 525-532.

[41] Theunissen, J., Ndakidemi, P. A., \& Laubscher, C. P. (2010). Potential of vermicompost produced from plant waste on the growth and nutrient status in vegetable production. International Journal of Physical Sciences, 5(13), 1964-1973.

[42] Tiwari, S. C., \& Husain, N. I. S. R. E. E. N. (2017). Biological activities and role of flavonoids in human health-A. Indian J Sci Res, 12(2), 193-6.

[43] Tukey, H. B., Marczynski S. (1984). Foliar nutrition-old ideas rediscovered. Acta Hort. 145: $205-212$.

[44] Wojcik, P. (2004). Uptake of mineral nutrients from foliar fertilization. Journal of fruit and ornamental plant research, 12 (Spec. ed.).

[45] Zainab, H., Nurfatirah, N., Norfaezah, A., \& Othman, H. (2016, June). Green bio-oil extraction for oil crops. In IOP Conf Ser Mater Sci Eng (Vol. 133, p. 12053).

[46] Zaniewicz-Bajkowska, A., Kosterna, E., Franczuk, J., \& Rosa, R. (2010). Yield quality of melon (Cucumis melo L.) depending on foliar feeding. Acta Sci. Pol., ser. Hort. Cultus, 9(1), 55-63.

Citation: Abdani D. Bandera, (2020). "Inorganic Fertilizers (Ground and Foliar Application) and Organic Fertilizer: Their Effects on the Growth and Yield of Pechay (Brassica napus L. subsp. chinensis var. Black Behi)", International Journal of Research Studies in Agricultural Sciences (IJRSAS), 6(5), pp. 38-55. DOI: http://dx.doi.org/10.20431/2454-6224.0606005

Copyright: (C) 2020Authors. This is an open-access article distributed under the terms of the Creative Commons Attribution License, which permits unrestricted use, distribution, and reproduction in any medium, provided the original author and source are credited. 